\title{
Recent advances in mechanistic studies on Ni catalyzed cross-coupling reactions
}

\author{
Zhe Li, Lei Liu* \\ Department of Chemistry, Tsinghua University, Beijing 100084, China
}

\section{A R T I C L E I N F O}

Article history:

Received 11 August 2014

Accepted 4 September 2014

Published 20 January 2015

\section{Keywords:}

Nickel

Homogeneous catalysis

Cross-coupling

C-C bond formation

Mechanism

\section{A B S T R A C T}

A variety of $\mathrm{Ni}$ catalyzed cross-coupling reactions have emerged as efficient new methods for the construction of $\mathrm{C}-\mathrm{C}$ bonds, and many mechanistic studies have been conducted to understand the factors controlling the reactivity and selectivity of $\mathrm{Ni}$ catalyzed reactions. The mechanisms of $\mathrm{Ni}$ catalyzed reactions are often very different from the corresponding Pd catalyzed processes because radical or bimetallic pathways are frequently involved in Ni catalyzed cross-coupling reactions. This review summarized recent advances in the mechanism of Ni catalyzed cross-coupling reactions. These are important for the development of new Ni catalyzed cross-coupling reactions with improved efficiency and selectivity.

(C) 2015, Dalian Institute of Chemical Physics, Chinese Academy of Sciences. Published by Elsevier B.V. All rights reserved.

\section{Introduction}

Transition metal catalyzed cross-coupling reactions between aryl/alkyl halides and organometallic reagents have been widely used to synthesize complex molecules and manufacture fine chemicals in modern organic chemistry [1-3]. Pd complexes are the most commonly used catalysts for many cross-coupling reactions such as the Suzuki reaction, Negishi reaction, Kumada reaction, and Heck reaction [4-6]. In contrast, Ni catalysts have been less developed for these transformations although they are lower cost alternatives to Pd catalysts. To overcome the limitation of $\mathrm{Ni}$ catalysis, $\mathrm{Ni}$ catalyzed cross-coupling reactions have been extensively investigated over the last decade, and a number of new transformations have been developed that have unique reactivity and selectivity [7-10]. More important is that many new Ni catalyzed reactions such as $\mathrm{C}-\mathrm{O}$ activation [11-13], alkyl-alkyl cross-coupling [14-17], and enantioselective cross-coupling [18-28] do not have Pd-catalyzed counterparts, showing that $\mathrm{Ni}$ catalysis has a unique place in organic synthesis. Compared to the rapid progress in experimental findings, many mechanistic aspects of the newly developed Ni catalyzed reactions remain to be elucidated. Mechanistic studies of Ni catalyzed cross-coupling reactions would give a more accurate understanding of how the Ni catalyzed cross-coupling reactions take place and provide important insights into the development of more efficient and selective synthesis methods.

Historically, Ni catalyzed cross-coupling reactions were first reported in the 1970s [29,30]. Kochi et al. [31] studied the mechanism of the oxidative addition of aryl halides to $\mathrm{Ni}(0)$ complexes in detail. As $\mathrm{Ni}$ is less electronegative than $\mathrm{Pd}$, the oxidative addition over $\mathrm{Ni}$ was easier, and the reductive elimination on the other hand was more difficult than Pd in the same oxidation state [32]. Thus Ni catalysts allow activation of less reactive electrophiles such as phenol derivatives, alkyl halides, and aryl fluorides [33]. In addition, $\beta$-hydride elimination with

\footnotetext{
*Corresponding author. Tel: +86-10-62780027; E-mail: lliu@mail.tsinghua.edu.cn This work was supported by the National High Technology Research and Development Program of China (863 Program, 2012AA02A700) and the National Natural Science Foundation of China (21221062). 
Ni was reported to be slower than with Pd [34] or thermodynamically disfavored [35]. The catalytic cycle of Pd-catalyzed reactions is usually a $\mathrm{Pd}(0) / \mathrm{Pd}(\mathrm{II})$ polar (non-radical) mechanism [36-39]. Similarly, many Ni catalyzed reactions are also based on a $\mathrm{Ni}(0) / \mathrm{Ni}(\mathrm{II})$ transformation. However, some Ni catalyzed reactions involve a $\mathrm{Ni}(\mathrm{I}) / \mathrm{Ni}(\mathrm{III})$ transformation or some more complicated catalytic cycles [40]. The facile accessibility of $\mathrm{Ni}(\mathrm{I})$ or $\mathrm{Ni}(\mathrm{III})$ complexes provides novel modes of reactivity and radical mechanisms [41-43].

In the present review, we summarized recent advances on the mechanism of $\mathrm{Ni}$ catalyzed cross-coupling reactions. $\mathrm{Hu}$ [44] recently wrote an excellent review of the mechanistic studies of $\mathrm{Ni}$ catalyzed reactions of alkyl halides. Sigman's group [45] also comprehensively summarized the progress in the $\mathrm{Ni}$ catalyzed cross-couplings of alkyl organometallic reagents. Thus in the present review we focused on the studies reported in the literature between 2011 and 2014. The contents are arranged according to the different types of Ni catalyzed reactions including conventional cross-coupling, reductive cross-coupling, and $\mathrm{C}-\mathrm{H}$ functionalization. Important compounds and intermediates mentioned in the text are numbered as 1, 2, 3, etc. according to the order of appearance. Calculated transition states are named as $\mathbf{T S}_{\boldsymbol{i}-\boldsymbol{j}}$ where $\boldsymbol{i}$ and $\boldsymbol{j}$ are the intermediates that precede and follow the transition state.

\section{Suzuki reaction}

Fu's group [46,47] reported an efficient $\mathrm{Ni}$ catalyzed cross-coupling reaction between a non-activated secondary alkyl halide with alkylboranes using L1 (trans- $N, N^{\prime}$-dimethyl1,2-cyclohexanediamine) and L2 (trans- $N, N^{\prime}$-dimethyl-1,2-diphenylethane-1,2-diamine) as ligands (Scheme 1). A Nil-NiII catalytic cycle was proposed that consisted of three key steps, namely, transmetallation, oxidative addition, and reductive elimination (Fig. 1). The same activation mode of alkyl halides was also proposed in a recent study by us for the Ni catalyzed borylation reaction of primary and secondary alkyl bromides [48].

To elucidate the mechanism and explain the reactivity of this reaction, theoretical calculations have been conducted [49]. The favored mechanism was proposed to consist of three steps (Fig. 2): 1) transmetallation of [ $\left.\mathrm{Ni}^{\mathrm{I}}(\mathbf{L 1}) \mathrm{X}\right]$ (1) with (9-BBN) $\mathrm{R}_{1}$ to produce $\left.\left[\mathrm{Ni}(\mathbf{L} 1)\left(\mathrm{R}_{1}\right)\right](3), 2\right)$ oxidative addition of $\mathrm{R}_{2} \mathrm{X}$ with $\left[\mathrm{Ni}(\mathrm{L} \mathbf{1})\left(\mathrm{R}_{1}\right)\right]$ to produce $\left[\mathrm{Ni}{ }^{\mathrm{III}}(\mathbf{L} 1)\left(\mathrm{R}_{1}\right)\left(\mathrm{R}_{2}\right) \mathrm{X}\right](6)$ in a radical pathway, and 3) $\mathrm{C}-\mathrm{C}$ reductive elimination to generate the final product and $\left[\mathrm{Ni}^{\mathrm{I}}(\mathbf{L} 1) \mathrm{X}\right]$. For both primary and secondary alkyl bromides, the transmetallation step was suggested to be the

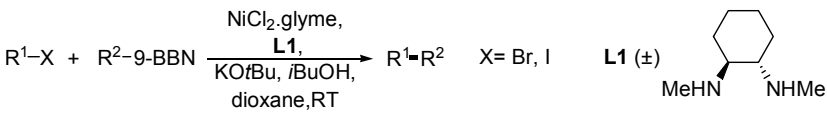

$$
\begin{aligned}
& \mathrm{R}^{1}-\mathrm{X}+\mathrm{R}^{2}-9-\mathrm{BBN} \frac{\mathrm{\textrm {NiBr } _ { 2 } \text { .diglyme, }}}{\mathrm{KOtBu,}, \mathrm{BuOH},} \mathrm{R}^{1}-\mathrm{R}^{2} \quad \mathrm{X}=\mathrm{Cl}, \mathrm{Br}, \mathrm{I} \quad \mathrm{L2}( \pm) \\
& R^{1}, R^{2}=\text { alkyl } \\
& \text { 9-BBN = 9-borabicyclo[3,3,1]nonane }
\end{aligned}
$$

Scheme 1. Ni catalyzed alkyl-alkyl Suzuki cross-coupling.

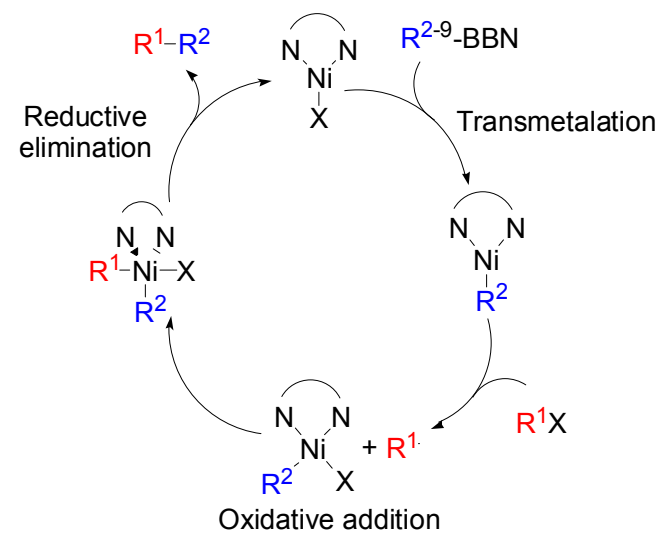

Fig. 1. Mechanism of Ni catalyzed alkyl-alkyl Suzuki cross-coupling.

turnover determining step via $\mathbf{T S}_{\mathbf{1 - 2}}$. The barrier of transmetallation was decreased by Koi-Bu which formed a potassium alkyl boronate salt with alkyl borane. The low reactivity of tertiary alkyl halides was explained by the high barrier of reductive elimination $(+34.7 \mathrm{kcal} / \mathrm{mol})$ compared to secondary alkyl halides $(+20.9 \mathrm{kcal} / \mathrm{mol})$. The $\mathrm{Ni}^{0}-\mathrm{Ni}^{\mathrm{II}}$ catalytic cycle is unfavorable because reductive elimination from both singlet and triplet dialkyl Ni complexes are very difficult.

The oxidative addition of the $\mathrm{C}-\mathrm{O}$ bond of allylic $\mathrm{N}, \mathrm{O}$-acetals to $\mathrm{Ni}(0)$ was reported by Doyle's group [20] to proceed through an ionic $\mathrm{S}_{\mathrm{N}} 1$-like mechanism facilitated by boronic acid in Suzuki cross-coupling (path i in Fig. 3). The stoichiometric reaction between $\mathrm{Ni}$ catalyst and substrate $\mathbf{5}$ does not take place if phenyl boroxine is absent (Fig. 4). Thus the $\mathrm{S}_{\mathrm{N}} 2$ (') pathway ii was excluded. To distinguish between pathways i and iii, the reaction between enantio-enriched complex 9 and 0.17 equiv. phenyl boroxine was conducted. The product is racemic $\mathbf{8 a}$, which is consistent with pathway i. The racemization was also shown to take place but this was not through the $\mathrm{Ni}(0)$ mediated displacement of the Ni-allyl complex because the concentration of $\mathrm{Ni}(0)$ did not influence the stereochemistry. Moreover, the product from enantio-enriched substrate 9 and MeMgBr has a conserved configuration, indicating that the configuration of Ni-allyl complex was stable. The secondary kinetic isotope effect (KIE) of $2-d_{1}-5$ was measured to be $1.13 \pm 0.02$, which is larger than a typical $S_{N} 2$-type oxidative addition $(0.94$

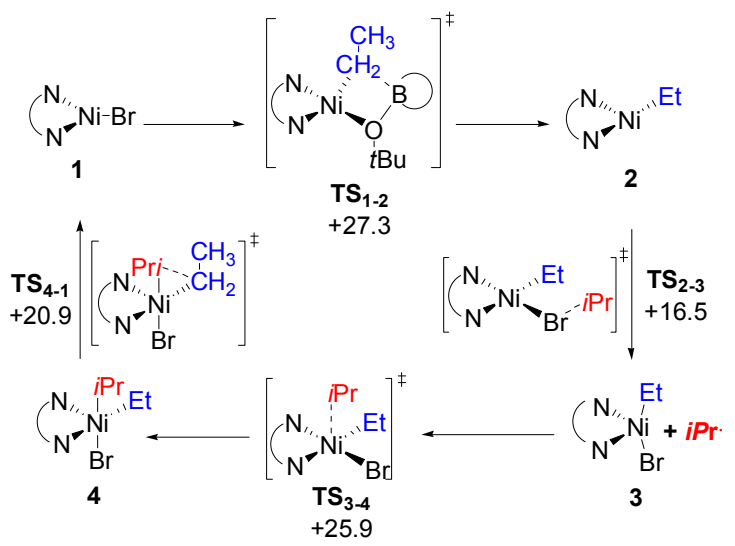

Fig. 2. Calculated free energy profile for the cross-coupling between alkyl halides and alkyl borane. 


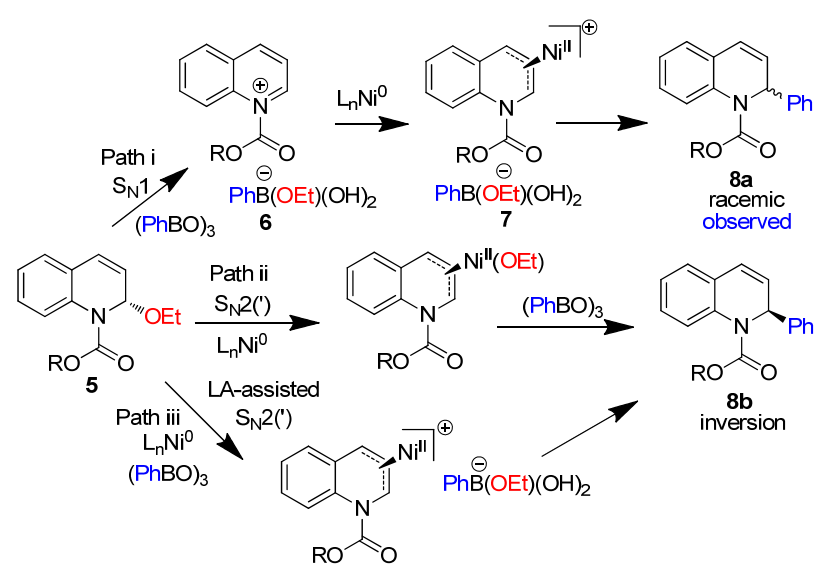

Fig. 3. Mechanism for the oxidative addition of $\mathbf{7}$ over a Ni catalyst.

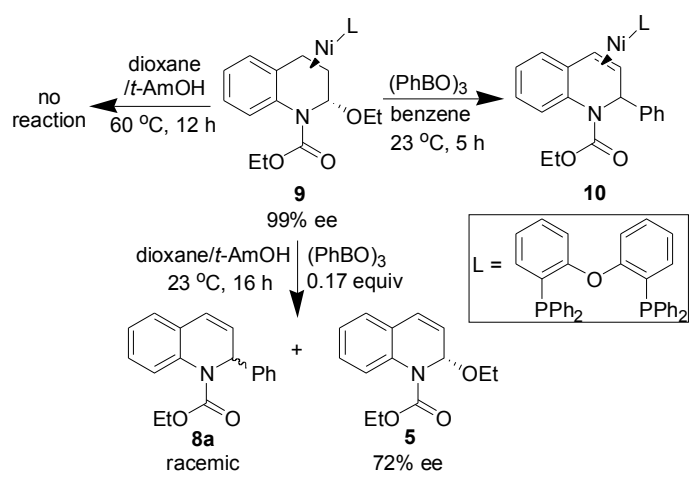

Fig. 4. Stoichiometric reactions between 9 and boronic acid.

to 1.05$)$. A KIE value as high as 1.53 has been observed in previously reported oxidative addition reactions with the $\mathrm{S}_{N} 1$ or radical mechanism. The fact that radical traps such as TEMPO (2,2,6,6-tetramethylpiperidine- $N$-oxide) and dihydroanthracene did not decrease the yield of $\mathbf{8 a}$ under otherwise standard conditions disproved a radical mechanism. These results indicated that the oxidative addition proceeded by the stepwise pathway i, in which the Lewis acidic boroxine abstracts the alkoxide leaving group to generate a quinolinium intermediate, and then the Ni catalyst attacks it from either of its prochiral faces.

The mechanism of $\mathrm{Ni}$ catalyzed cross-coupling of aryl fluorides (11) and aryl boronate ester (12) was studied by Chatani's group [50] (Scheme 2). $\mathrm{ZrF}_{4}$ was identified as the optimal additive affording the cross-coupling product $\mathbf{1 3}$ in $80 \%$ yield, whereas $\mathrm{ZrCl}_{4}$ led to no cross-coupling product. The reaction did not occur at all without the addition of $\mathrm{CsF}$, even in the presence of $\mathrm{ZrF}_{4}$. This implied that $\mathrm{ZrF}_{4}$ is not a simple fluoride donor that converts boronate ester into the activated tetra-coordinated borate species. The electronic nature of aryl fluoride has a significant impact on the reaction yield. Aryl fluorides with electron withdrawing substituents such as $\mathrm{CF}_{3}$, ester, and ketone afford good yields. Interestingly, substituents with strong resonance effects, including para-ketone, phenyl and phenyl ketone groups, gave higher yields than that with $p-\mathrm{CF}_{3}$ in phenyl fluoride. However, electron-rich aryl fluorides gave low yields under the same reaction conditions (e.g., 28\% for 4-fluoroanisole). An alternative method to facilitate $\mathrm{C}-\mathrm{F}$

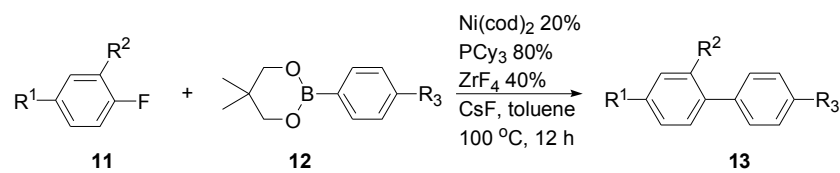

Scheme 2. Ni catalyzed Suzuki cross-coupling of aryl fluorides.

activation is to utilize ortho-directing groups. The crosscoupling between 2-(2-fluorophenyl)pyridine and boronic ester afforded $88 \%$ yield of product in the absence of metal fluoride salts. Both electron-rich and electron-poor aryl boronic esters can undergo this cross-coupling reaction efficiently. The cross-coupling between fluorobenzene and a mixture of electron-deficient and electron-rich boronic esters $\left(\mathrm{R}^{3}=\mathrm{CF}_{3}\right.$ and $\mathrm{NMe}_{2}$ in Scheme 2) produced the corresponding biaryls in a ratio of 51:49. In contrast, the competitive reaction using 2-(2-fluorophenyl)pyridine mainly gave the product from the electron-deficient boronic ester with a ratio of 70:30. This difference implies a change in the turnover limiting step.

A mechanism similar to the typical cross-coupling reaction mechanisms was proposed for this reaction [50]. This mechanism consists of three main steps (Fig. 5): oxidative addition of the C-F bond to NiLn (14) (step i), transmetallation (step ii), and reductive elimination (step iii). For aryl fluorides without directing groups, the oxidative addition was proposed to be the turnover determining step. For substrates bearing directing groups, the formation of a stable cyclometalated complex 16b was proposed to promote the oxidative addition, which renders steps ii and iii kinetically more favorable. This rationale was supported by the fact that the cross-coupling of bromo- and iodobenzene, in which transmetallation would be rate limiting, generated products from electron-deficient boronate esters much faster than from electron-rich boronate esters. The higher reactivity of electron-deficient boronate esters in the transmetallation step can be explained by the more facile formation of the activated boronate $\mathbf{1 8}$ although the opposite electronic effects have also been reported [51].

Zhao's group [52] in a theoretical study proposed that potassium phosphate is directly involved in the transmetallation step in Ni catalyzed Suzuki reaction. The mechanism of Ni catalyzed cross-coupling of aryl phosphates with aryl boronic acids

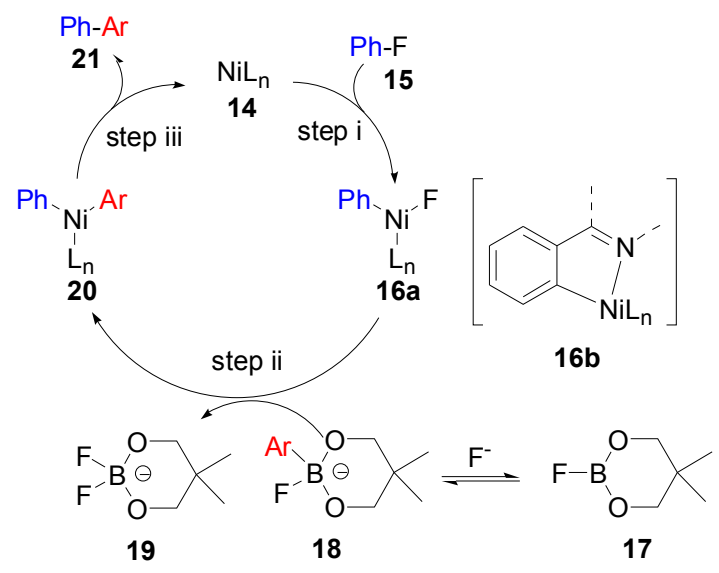

Fig. 5. Mechanism of Ni catalyzed cross-coupling between aryl fluoride and aryl boronic ester. 


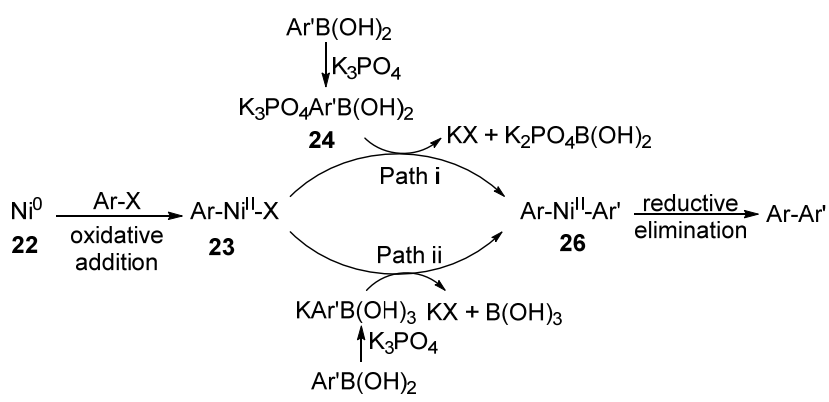

Fig. 6. Ni catalyzed cross-coupling between aryl fluoride and aryl boronic ester.

was proposed to consist of three steps: oxidative addition, transmetallation, and reductive elimination (Fig. 6). The catalytic cycle starts with the dissociation of one $\mathrm{PCy}$ ligand from $\mathrm{Ni}\left(\mathrm{PCy}_{3}\right)_{2}(22)$ to generate the complex $\mathrm{Ni}(\mathrm{PCy})\left[\eta^{2}-\mathrm{PhOP}(0)\right.$ $(\mathrm{OEt})_{2}$ ] by coordination of the substrate $\mathrm{PhOP}(\mathrm{O})(\mathrm{OEt})_{2}$. The following oxidative addition step generates $\mathrm{Ni}\left(\mathrm{PCy}_{3}\right)(\mathrm{Ph})$ $\left[\mathrm{OP}(\mathrm{O})(\mathrm{OEt})_{2}\right]$ (23), which reacts with aryl boronic acid in the transmetallation step. Aryl boronic acid was proposed to bind to potassium phosphate to form borophosphate (24) as the active species in the transmetallation (Path $i$ in Fig. 6). The overall barrier of this transmetallation was calculated to be $+30.2 \mathrm{kcal} / \mathrm{mol}$, a value consistent with the experimental temperature at $110{ }^{\circ} \mathrm{C}$. Finally, the $\mathrm{C}-\mathrm{C}$ reductive elimination step proceeds via a monophosphine pathway due to large steric repulsion between two $\mathrm{PCy}_{3}$ ligands.

\section{Negishi reaction}

A molecular $\left(\mathrm{Ni}^{\mathrm{I}} / \mathrm{Ni}^{\mathrm{III}}\right)$ mechanism was proposed for the cross-coupling between aryl halides (27) and diarylzinc reagents (28) catalyzed by $\mathrm{NiCl}_{2}$ and a $1,1^{\prime}, 1^{\prime \prime}$-(phosphanetriyl) tripiperidine ligand (Scheme 3) [53]. The nanoparticle mechanism which usually operates in the aminophosphine-based nickel catalytic system was excluded because of following experimental observations: (1) large excess of metallic mercury did not affect the rate or product yield; (2) excess (3.0 equiv.) $\mathrm{CS}_{2}$ only decreased the rate and yield slightly; (3) an additional amount ( 0.1 or 0.5 equiv.) of ligand had no effect on the rate or yield of the reaction; (4) the presence of $\mathrm{NBu}_{4} \mathrm{Br}$ did not affect either the rate or yield; (5) sigmoidal-shaped kinetics with an induction period which would indicate metal particle formation and autocatalytic surface growth was not observed; (6) UV/Vis spectra of the reaction mixture showed no evidence of nickel nanoparticles. Additional experimental observations indicated that the mechanism was a $\mathrm{Ni}^{\mathrm{I}} / \mathrm{Ni}^{\mathrm{III}}$ catalytic cycle involving radicals: (1) nitro-substituted aromatic halides inhibited the reaction; (2) the addition of (chloromethyl)benzene to the reaction mixture produced dibenzyl that was possibly formed from a

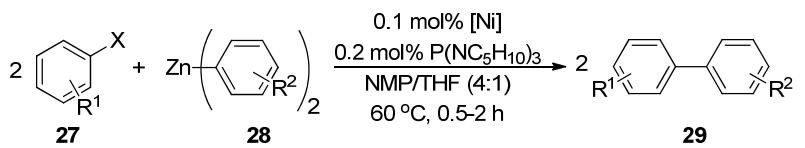

Scheme 3. Ni catalyzed cross-coupling between aryl halides and diarylzinc. single electron transfer from the metal center to the organic halide; (3) radical scavengers such as galvinoxyl, TEMPO, or dibenzyl viologen decreased the yield significantly; (4) the activity dropped dramatically when the reaction was performed under dioxygen.

The mechanism proposed for this reaction is shown in Fig. 7 [53]. The active catalyst $\left[\mathrm{Ni}^{1}\left(\mathrm{PR}_{3}\right)_{2}(\mathrm{X})\right](\mathbf{3 0})$ is generated either by the comproportionation of $\left[\mathrm{Ni}^{\mathrm{II}}\left(\mathrm{PR}_{3}\right)_{2}(\mathrm{X})_{2}\right]$ with $\left[\mathrm{Ni}^{0}\left(\mathrm{PR}_{3}\right)_{2}\right]$ or from the decomposition of $\left[\mathrm{Ni}^{\mathrm{III}}\left(\mathrm{PR}_{3}\right)_{2}(\mathrm{Ar})(\mathrm{X})\right]^{\bullet+}$, which was generated from the single electron transfer from $\left[\mathrm{Ni}\left(\mathrm{PR}_{3}\right)_{2}(\mathrm{Ar})(\mathrm{X})\right]$ to the aryl halide [54]. From $\left[\mathrm{Ni}^{\mathrm{I}}\left(\mathrm{PR}_{3}\right)_{2}(\mathrm{X})\right]$, two possible pathways (i) and (ii) were proposed. In catalytic cycle (i), the oxidative addition of $\mathbf{3 0}$ with $\operatorname{ArX}$ generates pentacoordinated complex $\left[\mathrm{Ni}^{\mathrm{III}}\left(\mathrm{PR}_{3}\right)_{2}(\mathrm{X})_{2}(\mathrm{Ar})\right] \quad$ (31). Competition experiments between different para-substituted aryl bromides and diarylzinc reagents showed a linear correlation between $\log \left(k / k_{\mathrm{H}}\right)$ and the Hammett substituent constants. The reaction rate decreased in the order $p-\mathrm{CF}_{3}>$ $p-\mathrm{C}(\mathrm{O}) \mathrm{CH}_{3}>p-\mathrm{F}>\mathrm{H}>p-\mathrm{OMe}>p$ - $\mathrm{NMe}_{2}$. These observations strongly indicated that the oxidative addition step is the rate determining step. Complex $\mathbf{3 1}$ can undergo transmetalation with diarylzinc reagents to produce $\left[\mathrm{Ni}{ }^{\mathrm{III}}\left(\mathrm{PR}_{3}\right)_{2}(\mathrm{X})(\mathrm{Ar})\left(\mathrm{Ar}^{\prime}\right)\right]$ (32), which generates the cross-coupling product, $\mathrm{Ar}-\mathrm{Ar}^{\prime}$ through a reductive elimination to complete the catalytic cycle. The catalytic cycle (ii) is less likely because the oxidative addition of (2,2'-bipyridine)(methyl)nickel(I) (similar to 33) to phenyl iodide was calculated to be less favored in computational studies [43]. However, a $\mathrm{Ni}^{0} / \mathrm{Ni}^{\mathrm{II}}$ mechanism consisting of the oxidative addition of aryl halide to $\left[\mathrm{Ni}^{0}\left(\mathrm{PR}_{3}\right)_{2}\right]$ and the formation of $\left[\mathrm{Ni}^{\mathrm{II}}\left(\mathrm{PR}_{3}\right)_{2}(\mathrm{Ar})(\mathrm{X})\right]$, subsequent transmetalation with diarylzinc to form $\left[\mathrm{Ni}^{\mathrm{II}}\left(\mathrm{PR}_{3}\right)_{2}(\mathrm{Ar})\left(\mathrm{Ar}^{\prime}\right)\right]$, and reductive elimination to produce the cross-coupling product cannot be excluded. Nevertheless, this mechanism is less likely because the reductive elimination of $\left[\mathrm{Ni}{ }^{I I}\left(\mathrm{PR}_{3}\right)_{2}(\mathrm{R})\left(\mathrm{R}^{\prime}\right)\right]$ was reported not to occur without it being oxidized to $\left[\mathrm{Ni}^{\mathrm{II}}\left(\mathrm{PR}_{3}\right)_{2}(\mathrm{R})\left(\mathrm{R}^{\prime}\right)\right]^{\bullet+}$ by aryl halides $[55,56]$. A similar $\mathrm{Ni}{ }^{I I} / \mathrm{Ni}^{\mathrm{IV}}$ mechanism was not considered because the oxidative addition of aryl halides to $\left[\mathrm{Ni}^{\mathrm{II}}\left(\mathrm{PR}_{3}\right)_{2}(\mathrm{R})\left(\mathrm{R}^{\prime}\right)\right]$ is unlikely [43].

In addition, aryl halides and $\mathrm{N}$-sulfonyl aziridines were reported to undergo cross-coupling with organozinc reagents by Doyle et al. [57] (Scheme 4). The major enantiomer in the product has an inverse configuration relative to the starting

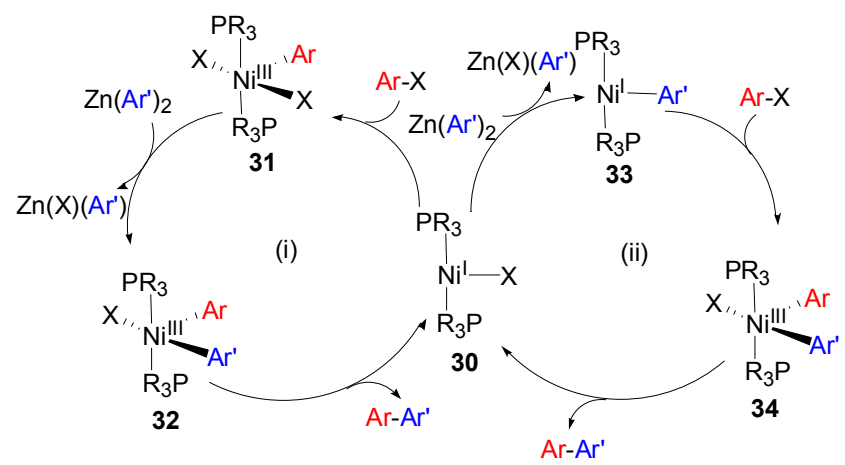

Fig. 7. Mechanism of Ni catalyzed cross-coupling between aryl halides and diarylzinc. 


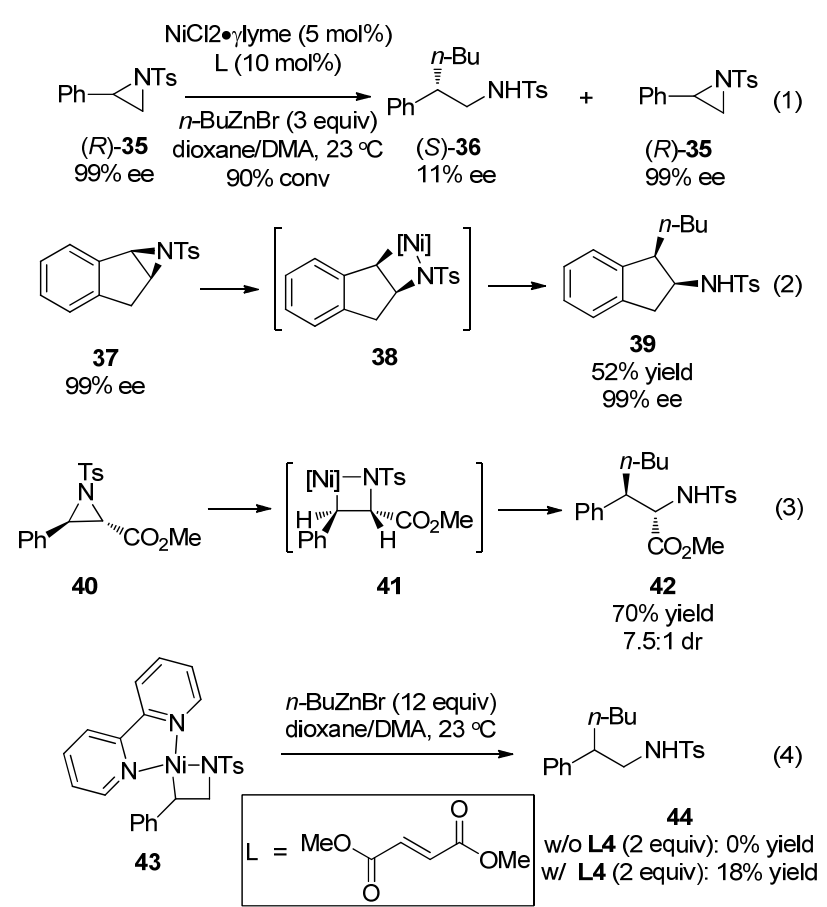

Scheme 4. Ni catalyzed cross-coupling between styrenyl aziridines and alkylzinc.

aziridine. Moreover, the ee value of the recovered reactant remained unchanged throughout the course of the reaction. For the indene-derived aziridine 37 , the $n$-butyl group is introduced on the same face of the indenyl ring as the sulfonamide via a metallacycle intermediate $\mathbf{3 8}$. For aziridine $\mathbf{4 0}$, the major diastereomer is generated from the more stable trans-azametallacycle 41. Sulfonamide coordination may also play an important role in preventing $\beta$-H elimination by constraining the conformation of the alkylnickel intermediates. A $\mathrm{Ni} / \mathrm{Ni}^{I I I}$ pathway was proposed to be unfavorable because $\mathrm{Ni}^{\mathrm{II}}$-azametallacycle $\mathbf{4 3}$ is a feasible substrate. The dimethyl fumarate ligand was expected to accelerate reductive elimination by coordination to the metal center.

Two possible mechanisms were proposed based on the experimental observations [57]. One involves an $\mathrm{S}_{\mathrm{N}} 2$-type oxidative addition followed by the reversible homolysis of the benzylic Ni-C bond (Fig. 8, path a). The other starts with an irreversible SET oxidative addition (Fig. 8, path b). The Hillhouse's [58] and Wolfe's [59] groups have demonstrated that the $\mathrm{S}_{\mathrm{N}} 2$ mechanism is favored for the oxidative addition of Ni to aliphatic $\mathrm{N}$-Ts aziridines. However, aliphatic aziridines are unreactive and the regioselectivity is opposite to what is expected in an $\mathrm{S}_{\mathrm{N}} 2$ process. The substrate scope and regioselectivity are similar to those in Ni catalyzed cross-coupling of alkyl halides, which have radical mechanisms. Nevertheless, it remains unclear how the SET mechanism would lead to dominant inversion of the configuration.

\section{Kumada-Corriu cross-coupling reaction}

In the Ni catalyzed Kumada-Corriu cross-coupling reaction of aryl halides, the oxidative addition of the $\mathrm{C}-\mathrm{X}$ bond to the $\mathrm{Ni}$

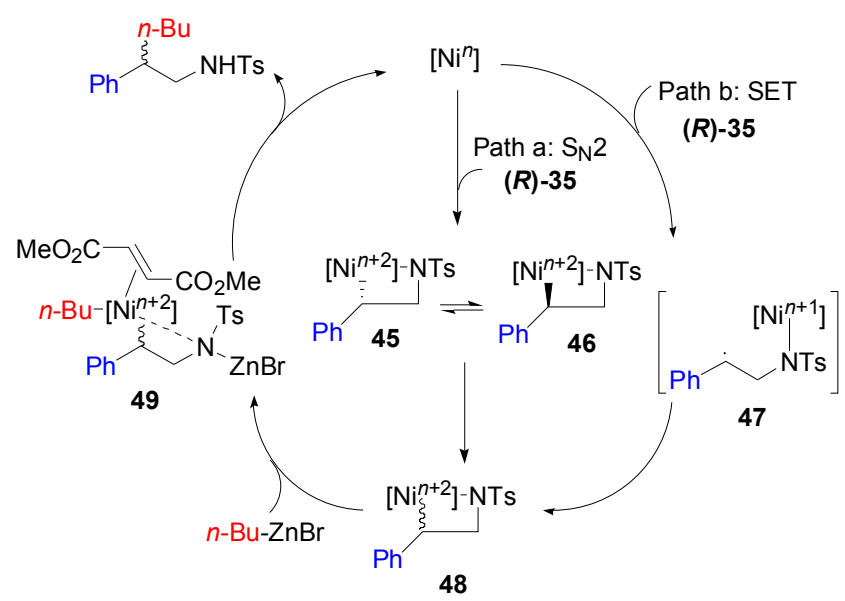

Fig. 8. Mechanism of the cross-coupling between styrenyl aziridines and alkylzinc.

complex requires an initial complex formation between the substrate and the Ni center. Recently, Locklin's group [60] studied the $\pi$-complexation between $\mathrm{Ni}(0)$ catalysts and haloarenes employing both the kinetic isotope effect (KIE) and DFT calculations. In the KIE experiment, an increased KIE of an atom indicates that this site is involved in the first irreversible step (FIS). The ${ }^{13} \mathrm{C}$ KIEs of all the carbons of the phenyl ring of $o$-bromotoluene and $o$-chlorotoluene were measured to increase in the cross-coupling with aryl or alkyl magnesium halides catalyzed by $\mathrm{Ni}(\mathrm{dppp})$ (dppp = 1,3-bis(diphenylphosphino) propane) (Scheme 5). This indicated that the $\pi$-complexation is the FIS, and once the Ni catalyst reacts with the aryl halides then the intramolecular oxidative addition occurs without dissociation of $\mathrm{Ni}(0)$. The binding energies of $\pi$-complexation were calculated by DFT methods to be 14-17 $\mathrm{kcal} / \mathrm{mol}$. The barrier of the ring walking steps was only 3-7 $\mathrm{kcal} / \mathrm{mol}$. Thus Ni(dppp) coordinates to the substrate in an $\eta^{2}$ fashion followed by ring walking (C1 to $\mathbf{C 6}$ in Fig. 9) and $\mathrm{Ni}$ insertion (TS).

A series of three-coordinate $\mathrm{Ni}(\mathrm{I})$ complexes with six-, seven-, and eight-membered ring N-heterocyclic carbenes were synthesized by Whittlesey's group [61] to investigate their catalytic activity. Complexes 50-53 were produced by the comproportionation reaction between [Ni(cod) 2$]$ and $\left[\mathrm{Ni}\left(\mathrm{PPh}_{3}\right)_{2} \mathrm{Br}_{2}\right]$ in the presence of appropriate carbene ligands (Scheme 6). The X-ray crystal structures showed that these $\mathrm{Ni}(\mathrm{I})$ complexes have distorted trigonal-planar geometries at the $\mathrm{Ni}$ center with $\mathrm{C}_{\text {carbene- }} \mathrm{Ni}-\mathrm{Br}$ angles much larger than $120^{\circ}$. Complexes 50-53 were examined as catalyst precursors for the cross-coupling reactions between electron-rich $p$-chlorotoluene and PhMgCl. Complex $\mathbf{5 0}$ was identified as the most effective catalyst. With a larger ring size and N-substituents, the catalyst activity decreased. The bulkier MesMgBr reagent was less reactive than $\mathrm{PhMgCl}$ under these catalytic conditions.

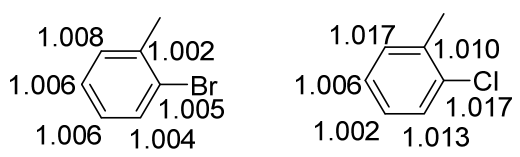

Scheme 5. KIEs of $o$-bromotoluene and $o$-chlorotoluene. 


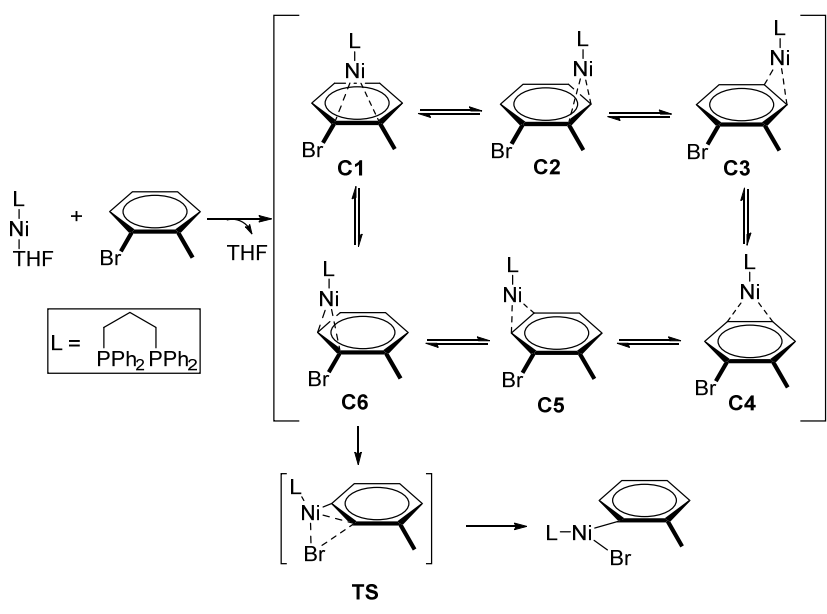

Fig. 9. Ring walking of Ni catalyst before oxidative addition.

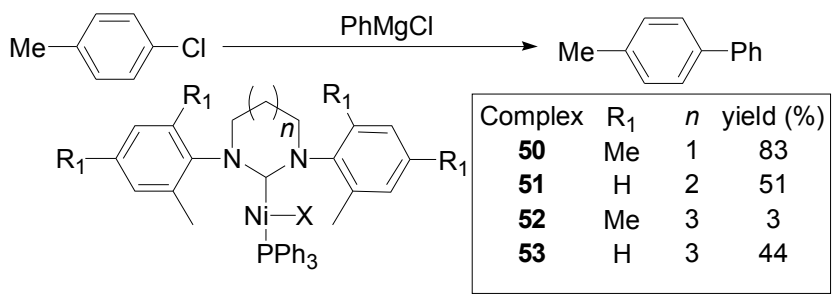

Scheme 6. Ni(I) complexes with NHC ligands as catalyst for Kumada cross-coupling.

These $\mathrm{Ni}(\mathrm{I})$ precursors were also tested in the cross-coupling between $\mathrm{Ar}-\mathrm{F}$ substrates and $\mathrm{ArMgX}$. However, the yields were very low (under $30 \%$ ). At present, it is not clear what oxidation states of $\mathrm{Ni}$ are present in the catalytic cycle.

Hu's group [62] recently proposed a mechanism involving a bimetallic oxidative addition through radical intermediates for the alkyl-alkyl Kumada coupling catalyzed by a $\mathrm{Ni}(\mathrm{II})$ pincer complex, $\left[\left(\mathrm{N}_{2} \mathrm{~N}\right) \mathrm{Ni}-\mathrm{Cl}\right]$ (Fig. 10). Complex 54 and one equivalent of $\mathrm{R}^{2} \mathrm{MgCl}$ produces a pre-equilibrium complex $\left[\left(\mathrm{N}_{2} \mathrm{~N}\right) \mathrm{NiCl}\right]\left(\mathrm{R}^{2} \mathrm{MgCl}\right)(56)$, which combines another equivalent of $\mathrm{R}^{2} \mathrm{MgCl}$ to form the transmetallation product $\left[\left(\mathrm{N}_{2} \mathrm{~N}\right) \mathrm{NiR}^{2}\right]\left(\mathrm{R}^{2} \mathrm{MgCl}\right)$ (57a). Complex $\mathbf{5 7 a}$ is in equilibrium with $\left[\left(\mathrm{N}_{2} \mathrm{~N}\right) \mathrm{NiR}^{2}\right](\mathbf{5 7 b})$, which is thermodynamically more stable but less reactive towards alkyl halides. The oxidative addition of complex 57a to $\mathrm{R}^{1} \mathrm{X}$ by an inner sphere single electron transfer step forms the alkyl radical $\mathrm{R}^{1} \bullet$ and $\mathrm{Ni}(\mathrm{III})$ complex $\left[\left(\mathrm{N}_{2} \mathrm{~N}\right) \mathrm{Ni}\left(\mathrm{R}^{2}\right) \mathrm{X}\right](\mathbf{5 8}) . \mathrm{R}^{2} \mathrm{MgCl}$ may dissociate from the $\mathrm{Ni}$ complex in this step. The $\mathrm{R}^{1} \bullet$ radical escapes from the solvent cage and then attacks another molecule of complex $\mathbf{5 7} \mathbf{a}$ or $\mathbf{5 7} \mathbf{b}$ to afford $\left[\left(\mathrm{N}_{2} \mathrm{~N}\right) \mathrm{Ni}\left(\mathrm{R}^{1}\right)\left(\mathrm{R}^{2}\right)\right](59)$. The reductive elimination of 58 gives the cross-coupling product $\mathrm{R}^{1}-\mathrm{R}^{2}$ and the formal $\mathrm{Ni}(\mathrm{I})$ complex $\left[\left(\mathrm{N}_{2} \mathrm{~N}\right) \mathrm{Ni}\right](\mathbf{6 0})$. The following comproportionation reaction between complexes $\mathbf{6 0}$ and $\mathbf{5 8}$ produces [ $\left.\left(\mathrm{N}_{2} \mathrm{~N}\right) \mathrm{NiX}\right]$ (55) and $\left[\left(\mathrm{N}_{2} \mathrm{~N}\right) \mathrm{NiR}^{2}\right](\mathbf{5 7 b})$ to regenerate the catalyst. Complex 57b has been isolated and shown to be a competent catalyst. However, 57b is not the active catalyst for the activation of alkyl halide. On the other hand, complex $\mathbf{5 7}$ a was proposed to be the key intermediate for the oxidative addition of alkyl halide. The binding of $\mathbf{M g}^{2+}$ to $\mathbf{5 7} \mathbf{b}$ is essential because alkyl lithium reagents cannot generate equally active species to that

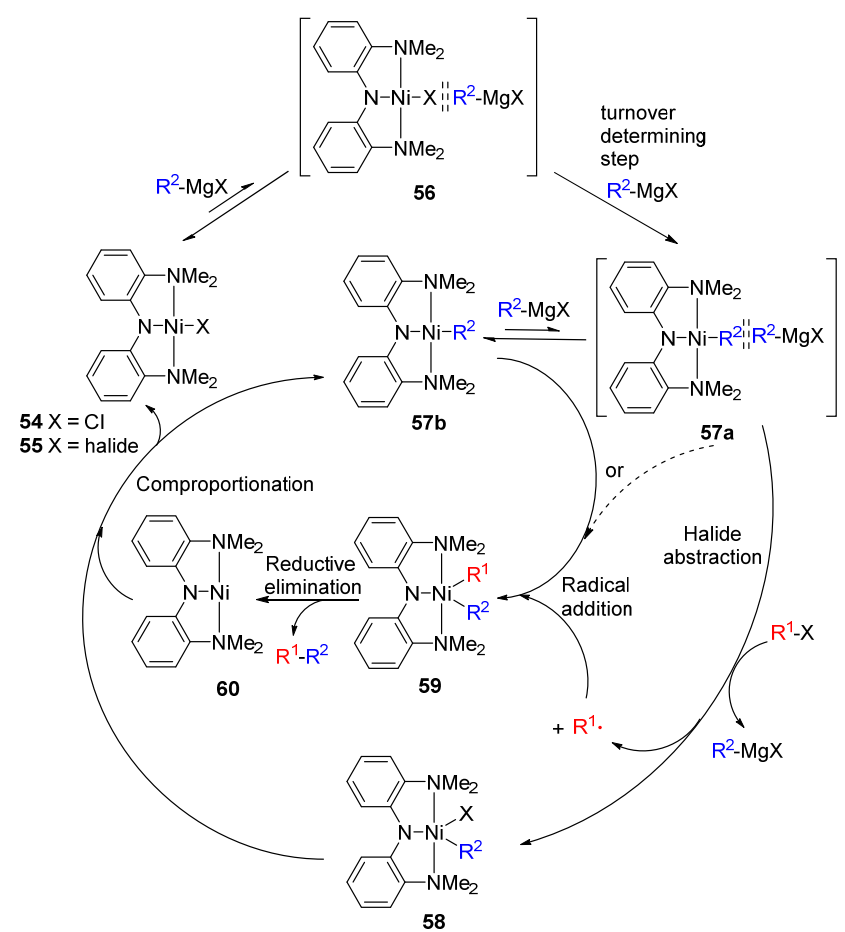

Fig. 10. Mechanism of alkyl-alkyl Kumada cross-coupling catalyzed by Ni complex $\mathbf{5 4}$.

from Grignard reagents. Complex $\left[\left(\mathrm{N}_{2} \mathrm{~N}\right) \mathrm{NiX}\right]$ was the resting state according to UV-Vis spectroscopy.

Several Ni(III) complexes have recently been characterized and studied in the context of cross-coupling reactions [63]. Complex 61 was synthesized by the oxidative addition of aryl halides to $\mathrm{Ni}(\mathrm{COD})_{2}$ in the presence of the ligand (Scheme 7). The geometry of complex $\mathbf{6 1}$ is a distorted octahedral with the tetradentate ligand. Complexes $\mathbf{6 1}$ and $\mathbf{6 2}$ can be oxidized to $\mathbf{6 1}^{+}$and $62^{+}$by 1 equiv. of ferrocenium hexafluorophosphate $\left[\mathrm{Fc}^{+}\right] \mathrm{PF}_{6}$. Complexes $\mathbf{6 1}^{+}$and $\mathbf{6 2}^{+}$are paramagnetic with effective magnetic moments $\mu_{\text {eff }}$ of 2.11-2.03 $\mu_{\mathrm{b}}$ corresponding to one unpaired electron. DFT calculations showed that $\mathbf{6 1}^{+}$is a metal-based radical with $>98 \%$ spin density on the $\mathrm{Ni}$ center. Complex 61 reacts with $\mathrm{MeMgCl}$ to generate the transmetallation product $63\left[(\mathrm{~L}) \mathrm{Ni}^{\mathrm{II}}(\mathrm{PhF}) \mathrm{Me}\right]$ with a square planar geometry for the Ni center (Scheme 8). The dissociation of the two axial $\mathrm{N}$ of the ligand in $\mathbf{6 3}$ is presumably due to the presence of two strong $\sigma$-donor organic ligands. When $\mathbf{6 3}$ is oxidized by $\left[\mathrm{Fc}^{+}\right] \mathrm{PF}_{6}$ in $\mathrm{MeCN}, \mathrm{C}-\mathrm{C}$ reductive elimination occurs to form $p$ - $-\mathrm{C}_{6} \mathrm{H}_{4}-\mathrm{Me}$ in $61 \%$ yield. Complex $63^{+}$is proposed to be the intermediate for this process. The reaction between $61^{+}$and

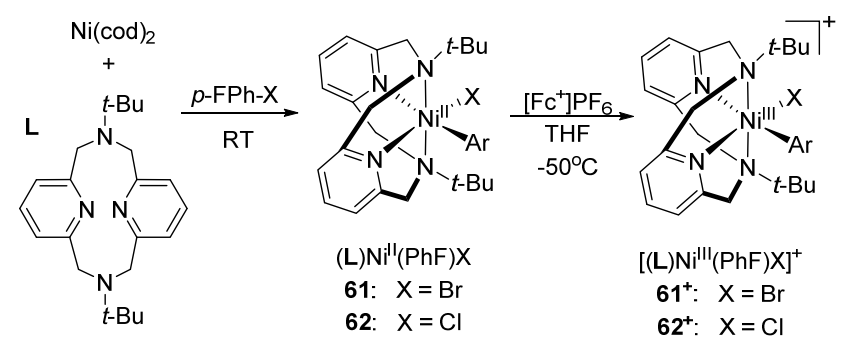

Scheme 7. Synthesis of Ni(III) complexes. 


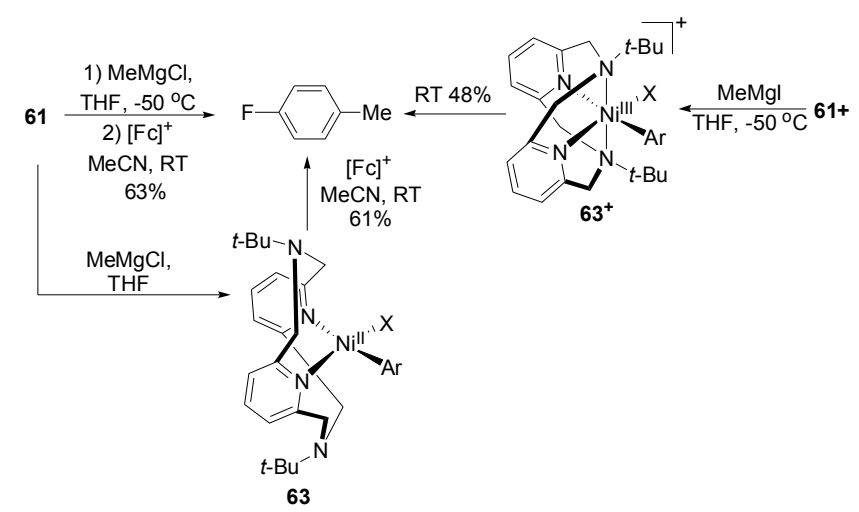

Scheme 8. Reactions between Ni(III) complexes and MeMgCl.

MeMgI also generates $\mathbf{6 3}^{+}$, which affords $p$-F-C $6 \mathrm{H}_{4}-\mathrm{Me}$ upon warming.

Complexes $\mathbf{6 1}$ or $\mathbf{6 1 +}$ were found to be active catalysts for Kumada and Negishi cross-coupling reactions (Scheme 9) [63]. The cross-coupling of iodotoluene with $\mathrm{PhMgBr}$ has non-optimized yields of $70 \%$ when catalyzed by $\mathbf{6 1}$ or $\mathbf{6 1}^{+}$, whereas the coupling between iodoheptane and an alkyl Grignard has $27 \%$ yield when catalyzed by $\mathbf{6 1}+$. Negishi coupling between iodoethylbenzene and 1-octylzinc bromide catalyzed by $\mathbf{6 1}$ or $\mathbf{6 1} \mathbf{1}^{+}$have yields of $23 \%$ and $20 \%$, respectively. It is interesting that when 61 was treated with iodoethylbenzene, the EPR spectrum indicated the presence of [NiII(aryl)(halide)] and [NiII(aryl)(alkyl)] species. In addition, for the above cross-coupling reactions, adducts between the organonickel intermediates and the solvent were observed. These observations supported radical mechanisms for both cross-coupling reactions. This study of Ni(III) complexes provided possibilities to further investigate the detailed mechanisms of Ni catalyzed cross-coupling reactions.

\section{Heck reaction}

Jarvo's group [64] has reported Ni catalyzed enantiospecific intramolecular Heck reactions of secondary benzylic ethers (Scheme 10). The stereochemistry of the cyclization product of trans- $( \pm)-64$ is consistent with configuration inversion at the benzylic stereogenic carbon. This indicated configurational

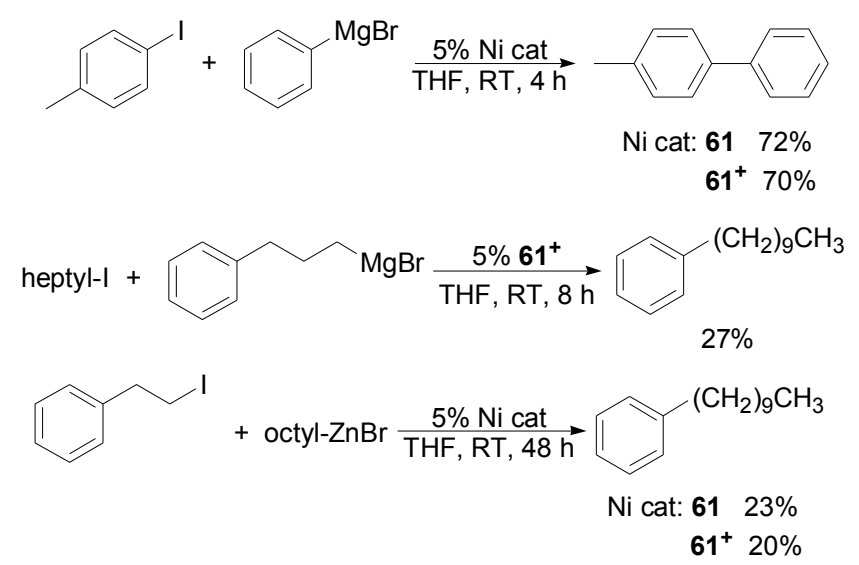

Scheme 9. Negishi reactions catalyzed by Ni(III) complexes.

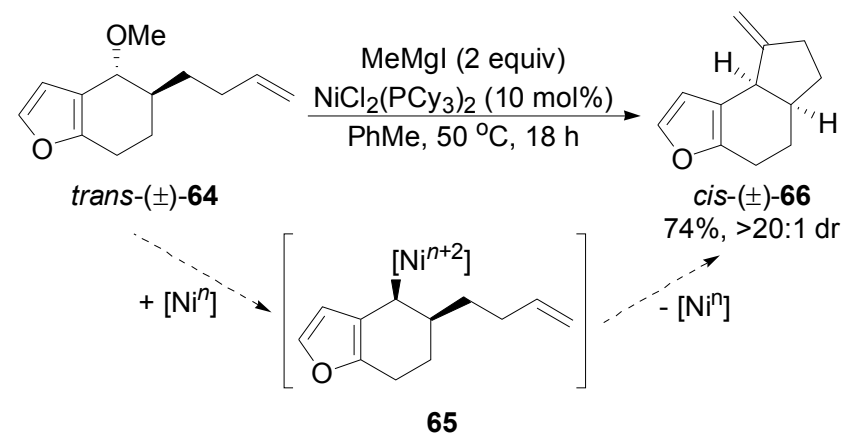

Scheme 10. Ni catalyzed enantiospecific intramolecular Heck reactions of secondary benzylic ethers.

inversion in the oxidative addition step to generate the benzylnickel complex 65 . The substrate cis- $( \pm)-64$ did not undergo Heck cyclization nor Kumada coupling. This observation is consistent with the binding of the olefin to the Ni catalyst before the oxidative addition. The stereochemistry of the olefin insertion and $\beta-\mathrm{H}$ elimination steps implied that the mechanisms of these steps are similar to classical Heck reactions. The substrates $(E)-67$ and $(Z)-67$ afford $(E)-68$ and $(Z)-68$ with a high stereospecificity at both the double bond and the benzylic carbon (Scheme 11). Thus Ni complexes 69 and 70 were proposed as the intermediates prior to $\beta$-H elimination.

\section{Sonogashira reaction}

Hartwig's group [65] synthesized complexes $\mathbf{7 1}$ and $\mathbf{7 2}$ to investigate the elementary steps of $\mathrm{Ni}$ catalyzed Sonogashira reactions (Scheme 12). Complex $\mathbf{7 1}$ was synthesized by the reaction between $\mathrm{SiCHSi}$ (see the structure of ECHE, E=Si, Ge, and $\mathrm{P}$ in Scheme 12) and $\mathrm{NiBr}_{2}(\mathrm{dme})$ (dme = 1,2-dimethoxyethane) under basic conditions. Complex 72 can also be synthesized by this reaction in a lower yield, or by the reaction of GeCBrGe and Ni(cod)2. Both $\mathbf{7 1}$ and $\mathbf{7 2}$ have a square planar
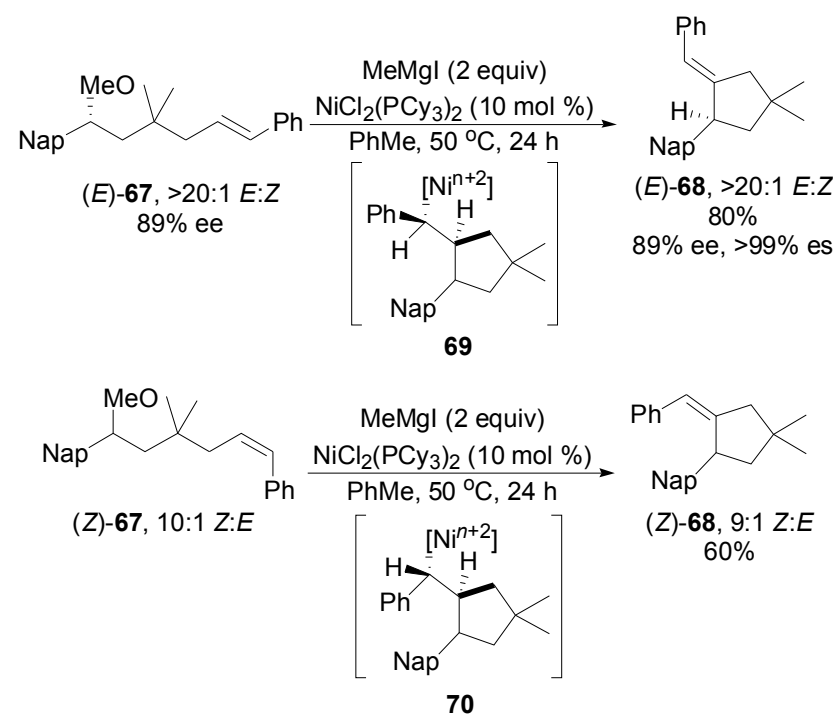

Scheme 11. Ni catalyzed enantiospecific intramolecular Heck reactions of $(E) /(Z)-67$. 


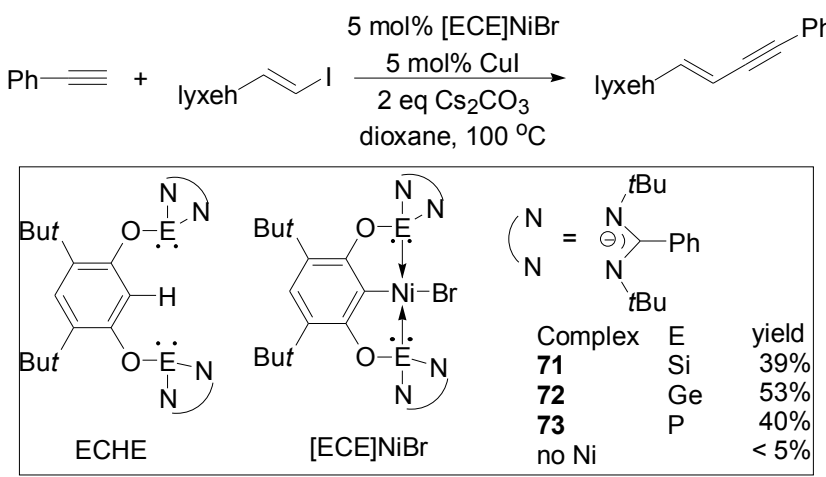

Scheme 12. [ECE]NiBr catalyzed Sonogashira cross-coupling.

geometry. An isoelectronic PIII complex [PCP] $\mathrm{NiBr}$ (73) was also synthesized for comparison. The $\mathrm{C}_{\mathrm{ipso}}-\mathrm{Ni}$ bonds of $\mathbf{7 1}$ and $\mathbf{7 2}$ are $5-8 \mathrm{pm}$ longer than that of $\mathbf{7 3}$ because the $\sigma$-donor strengths of Ge and Si are stronger than PIII. This effect is less for the $\mathrm{Ni}-\mathrm{Br}$ bond lengths where an increment of about $1 \mathrm{pm}$ was observed in the order of $\mathrm{Si}>\mathrm{Ge}>\mathrm{P}$.

Complexes 71-73 were found to be catalysts for the Sonogashira cross-coupling reaction with moderate yields [65]. The stoichiometric reactions between $\mathbf{7 1}$ or $\mathbf{7 2}$ and copper phenyl acetylides produce $\mathrm{Ni}$ phenylacetylide complexes [ECE]Ni-C $\equiv \mathrm{C}$-ter $\mathrm{Ph} \rightarrow \mathrm{CuBr}$ (74 and 75 in Scheme 13), which have been successfully characterized by X-ray diffraction. The addition of $(E)$-1-iodo-1-octene to the solution of $\mathbf{7 4}$ generates the $\mathrm{C}-\mathrm{C}$ cross-coupling product in high yield together with [SiCSi]NiI. Although no other reaction intermediates were isolated in this reaction, the mechanism was proposed to consist of three main steps: the transmetallation between [ECE]NiX and copper phenylacetylide, the following oxidative addition of alkenyl halide to [ECE] $\mathrm{Ni}-\mathrm{C} \equiv \mathrm{C}-\mathrm{Ar} \rightarrow \mathrm{CuBr}$ complex, and reductive elimination to produce [ECE] NiX and the cross-coupling product.

We recently reported the first $\mathrm{Ni}$ catalyzed Sonogashira reaction of non-activated secondary alkyl bromides and iodides using readily available bis(oxazoline) ligands (Scheme 14) [66]. The scope of this reaction included both cyclic and acyclic alkyl halides. Both aryl and alkyl alkynes can be transformed. Common functional groups such as ketal, amide, amine, carbamate, and heterocycles were compatible with this reaction. The reac-

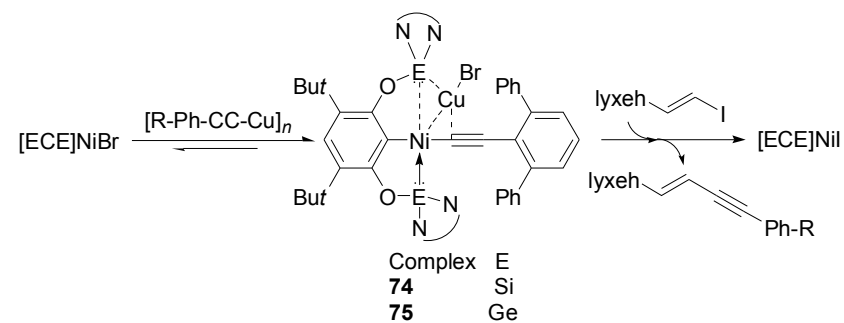

Scheme 13. Mechanism of [ECE]NiBr catalyzed Sonogashira crosscoupling.

tion between 6-iodoheptene $\mathbf{7 6}$ and alkyne $\mathbf{7 7}$ produced $15 \%$ yield of the linear product $\mathbf{7 8}$ and $50 \%$ yield of the cyclization product 79 which implied a 5-exo-cyclization process. The cross-coupling of (bromomethyl)cyclopropane $\mathbf{8 0}$ and alkyne $\mathbf{8 1}$ afforded the ring opening product $\mathbf{8 2}$ alone in $65 \%$ yield. Based on the above observations, a radical mechanism was proposed: the catalytic cycle begins with an alkynyl-Ni ${ }^{\mathrm{I}}$ complex which is oxidized by a ligand-based one electron process to generate the $\mathrm{Ni}^{\mathrm{II}}$ complex, and the following oxidative radical addition produces the $\mathrm{Ni}^{\mathrm{III}}$ complex which undergoes $\mathrm{C}-\mathrm{C}$ reductive elimination to afford the cross-coupling product and regenerates the $\mathrm{Ni}^{\mathrm{I}}$ complex to initiate the next catalytic cycle. This mechanism was supported by the observed stereochemistry in the cross-coupling between terminal alkynes and 1,3and 1,4- substituted cyclohexyl iodides. In addition, TEMPO was found to be a potent inhibitor of this reaction.

\section{Cross-coupling involving $\mathrm{C}-\mathrm{H}$ activation}

Itami's group [67] reported the $\mathrm{Ni}(\operatorname{cod})_{2} /$ dcype $($ dcype $=$ 1,2-bis(dicyclohexylphosphino)ethane) catalyzed cross-coupling reactions between aryl esters and azoles to produce the decarbonylative $\mathrm{C}-\mathrm{H}$ coupling products (Scheme 15). The same catalyst can also be applied to the $\mathrm{C}-\mathrm{O} / \mathrm{C}-\mathrm{H}$ cross-coupling reaction between phenol esters and azoles [68]. For the decarbonylative $\mathrm{C}-\mathrm{H}$ cross-coupling, a mechanism consisting of oxidative addition of $\mathrm{C}($ aryl)-O bond, $\mathrm{CO}$ migration, azole $\mathrm{C}-\mathrm{H}$ nickelation, reductive elimination, and $\mathrm{CO}$ extrusion was proposed [67] (Fig. 11). For the $\mathrm{C}-\mathrm{O} / \mathrm{C}-\mathrm{H}$ cross-coupling, the catalytic cycle was suggested to involve the oxidative addition of $\mathrm{C}$ (phenyl)-O bond, $\mathrm{C}-\mathrm{H}$ nickelation, and reductive elimination

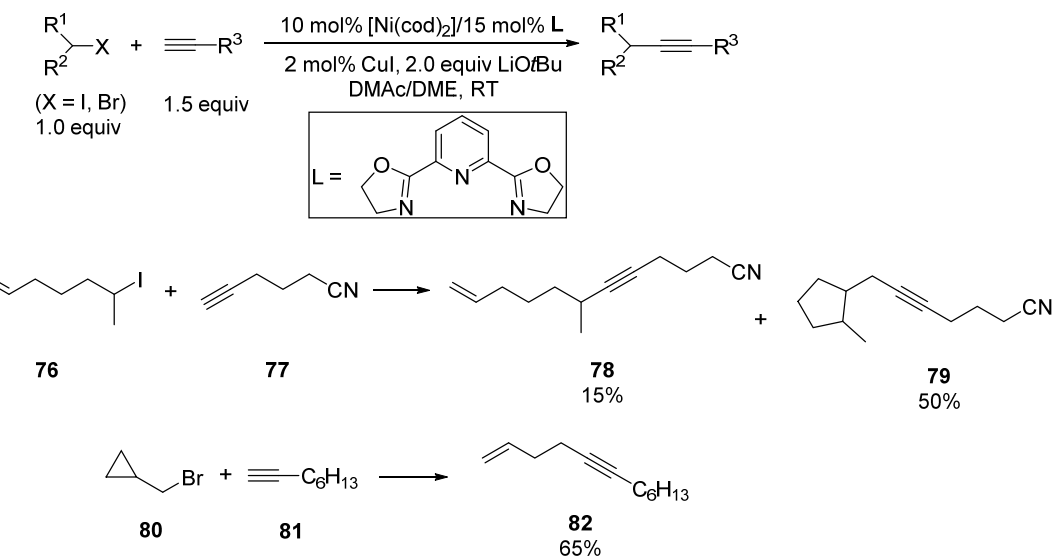

Scheme 14. Ni catalyzed Sonogashira reaction of non-activated secondary alkyl halides. 


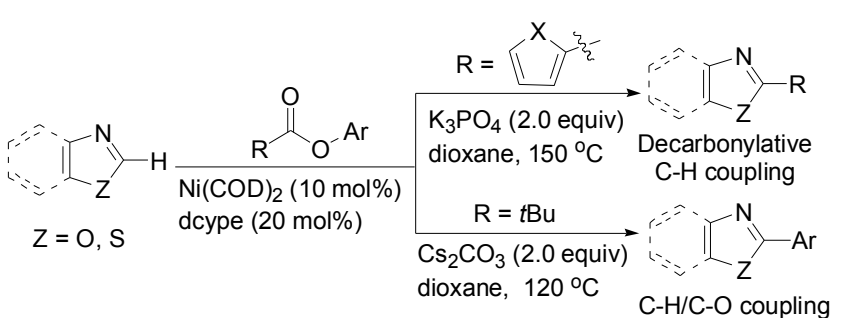

Scheme 15. Chemoselectivity of Ni catalyzed cross-coupling reactions between aryl esters and azoles.

steps [68].

To investigate the origin of this interesting chemoselectivity, theoretical studies on the mechanism of Ni catalyzed coupling reactions between azoles and aryl carboxylates have been separately conducted by Houk's group [69] and Fu's group [70]. Houk et al. found that $\mathrm{C}($ acyl $)-\mathrm{O}$ activation by Ni catalyst with a bidentate phosphine ligand is more feasible than the $\mathrm{C}(\operatorname{aryl})-0$ bond because the low bond dissociation energy of the $\mathrm{C}(\mathrm{acyl})-\mathrm{O}$ bond leads to a lower distortion energy of the transition state. In contrast, $\mathrm{Ni}(0)$ complex with a monophosphine ligand favors $\mathrm{C}(\operatorname{aryl})-0$ bond cleavage because the vacant coordination site on $\mathrm{Ni}$ provides a stabilizing interaction with the substrate. For aryl pivalates, $\mathrm{Ni}(0)$ complex with a bidentate phosphine favors $\mathrm{C}($ acyl)-O activation over C(aryl)-O activation. However, the decarbonylation step after the $\mathrm{C}($ acyl)-O activation has a very high barrier. Thus the subsequent $\mathrm{C}-\mathrm{H}$ activation of azoles only occurs after C(aryl)-0 activation.

Fu's group [70] found that the CO migration step was the turnover determining step for decarbonylative $\mathrm{C}-\mathrm{H}$ cross-coupling and it occurs after the $\mathrm{C}-\mathrm{H}$ activation of azole in the decarbonylative $\mathrm{C}-\mathrm{H}$ cross-coupling reaction. The reason is that the $\mathrm{Ni}(\mathrm{II})$ center (85) generated by the CO migration step would be too electron deficient for subsequent $\mathrm{C}-\mathrm{H}$ activation to occur. For the $\mathrm{C}-\mathrm{O} / \mathrm{C}-\mathrm{H}$ cross-coupling, a catalytic pathway similar to Itami's original proposal was calculated to be favored. The base-promoted $\mathrm{C}-\mathrm{H}$ activation of azole was found to be the turnover determining step. The calculated difference of the barriers was consistent with the experimental chemoselectivity. Furthermore, the steric effect of the acyl moiety has a

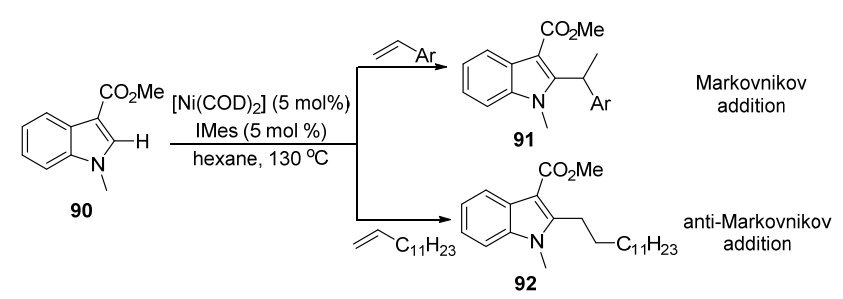

Scheme 16. Ni catalyzed hydroheteroarylation of vinlyarenes.

significant influence on the barrier of CO migration in the decarbonylative $\mathrm{C}-\mathrm{H}$ coupling mechanism. To the contrary, the overall energy demand is independent on the acyl moiety in the $\mathrm{C}-\mathrm{H} / \mathrm{C}-\mathrm{O}$ coupling mechanism because the carboxylate is released before the turnover determining step. As a result, the decarbonylative $\mathrm{C}-\mathrm{H}$ cross-coupling is favored for $\mathrm{C}-\mathrm{O}$ electrophiles with bulky aryl esters, while the $\mathrm{C}-\mathrm{H} / \mathrm{C}-\mathrm{O}$ cross-coupling prevails with more bulky phenol esters such as phenyl pivalate and triflate.

Hiyama's group [71] reported a Ni catalyzed hydroheteroarylation of vinlyarenes. The regioselectivity of this reaction was controlled by the substituent on the alkenes: the additions of fluoroarenes or heteroarenes 90 to aryl olefin produce Markovnikov adduct 91, whereas the addition product of alkyl olefin is anti-Markovnikov 92 (Scheme 16). The mechanism was proposed to begin with the reversible oxidative addition of Ar-H bond from 93 to 94 (Fig. 12), followed by reversible hydronickelation of olefins from 94 to 96 and irreversible C-C reductive elimination.

In a following theoretical study, Shi's group [72] found that the calculated catalytic pathway was consistent with the experimental evidence with $\mathrm{C}-\mathrm{C}$ reductive elimination as the turnover determining step. Furthermore, they found that the Markovnikov product of aryl olefin was facilitated by the secondary orbital overlap between $\mathrm{Ni}$ and the aryl moiety in the transition state of the $\mathrm{C}-\mathrm{C}$ reductive elimination. It was predicted that electron deficient para-substituents on the aryl olefin would enhance the Markovnikov selectivity. On the other hand, there is no secondary orbital interaction in the $\mathrm{C}-\mathrm{C}$ reductive elimination step of the reaction between alkyl olefin

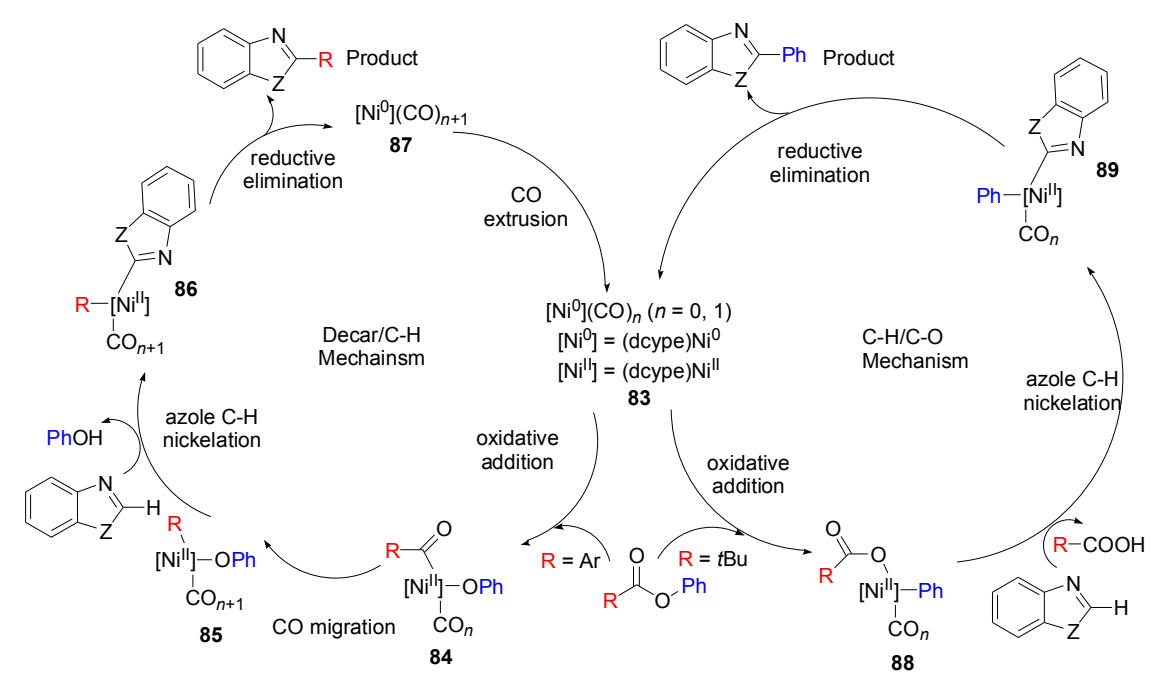

Fig. 11. Mechanism of Ni catalyzed cross-coupling reactions between aryl esters and azoles. 


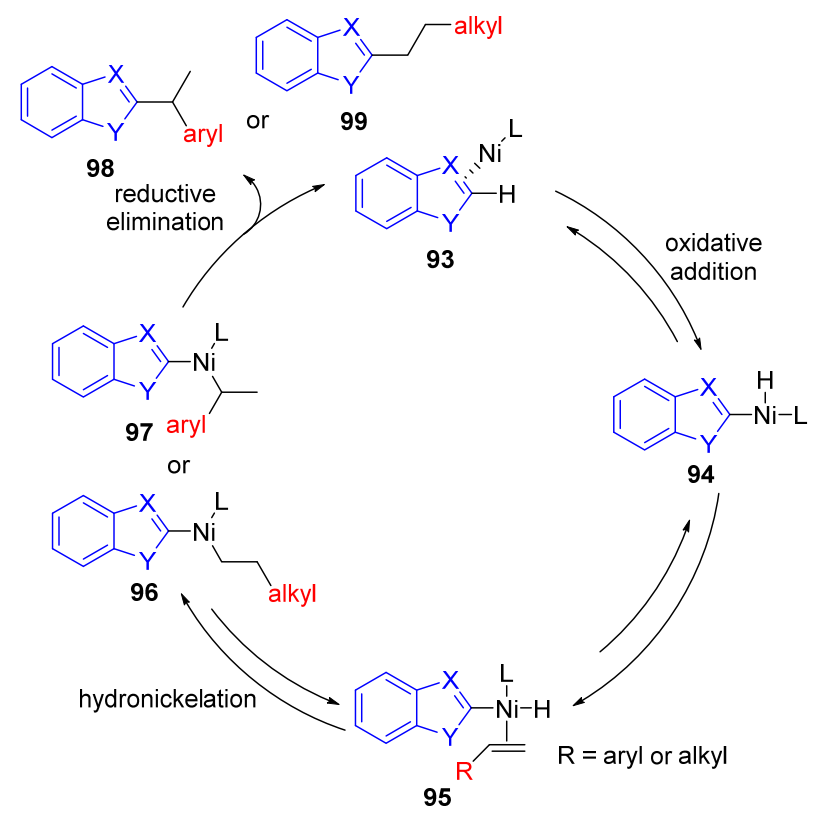

Fig. 12. Mechanism of $\mathrm{Ni}$ catalyzed hydroheteroarylation of vinlyarenes.

and heteroarenes. More bulky alkyl substituents were calculated to favor anti-Markovnikov selectivity.

\section{Reductive cross-coupling}

The cross-coupling of an aryl halide and an alkyl halide is a versatile synthetic method without the need of a carbon nucleophile. Weix's group [73] studied the mechanism of Ni catalyzed cross-coupling of aryl halides with alkyl halides (Scheme 17). The mechanism was proposed to begin with the selective oxidative addition of bypridine-ligated $\mathrm{Ni}(0)$ to iodobenzene over alkyl iodide to produce an arylnickel(II) complex [(L)Ni(Ph)I] (100) (Fig. 13). This complex 100 is the resting state of the catalyst and reacts with an alkyl radical $\mathrm{RCH}_{2} \bullet$ to generate a diorganonickel(III) complex [(L)Ni(RCH 2$)(\mathrm{Ph}) \mathrm{I}]$ (101). The following $\mathrm{C}-\mathrm{C}$ reductive elimination produces the cross-coupling product $\mathrm{Ph}-\mathrm{CH}_{2} \mathrm{R}$ and [(L)NiI] (103). Complex 103 reacts with alkyl iodide to produce the $\mathrm{RCH}_{2} \bullet$ radical and [(L)Nil2] (104). Then 104 is reduced by manganese to regenerate the $\mathrm{Ni}(0)$ catalyst. The initiation step has not been studied in detail. However, the $\mathrm{RCH}_{2} \bullet$ radical can be generated by the
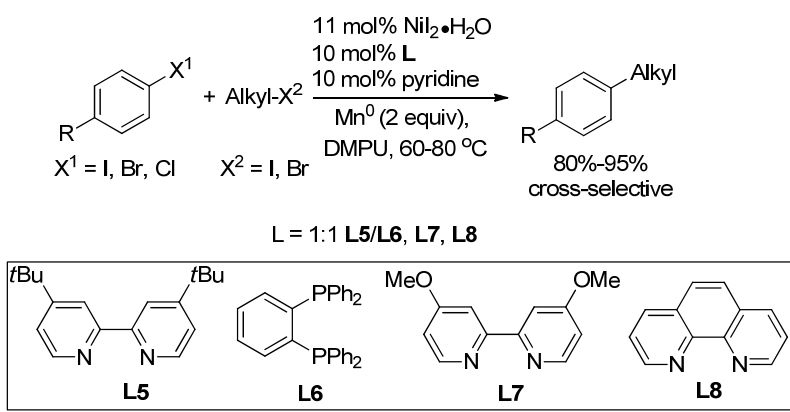

Scheme 17. Ni catalyzed reductive cross-coupling of an aryl halide and an alkyl halide.

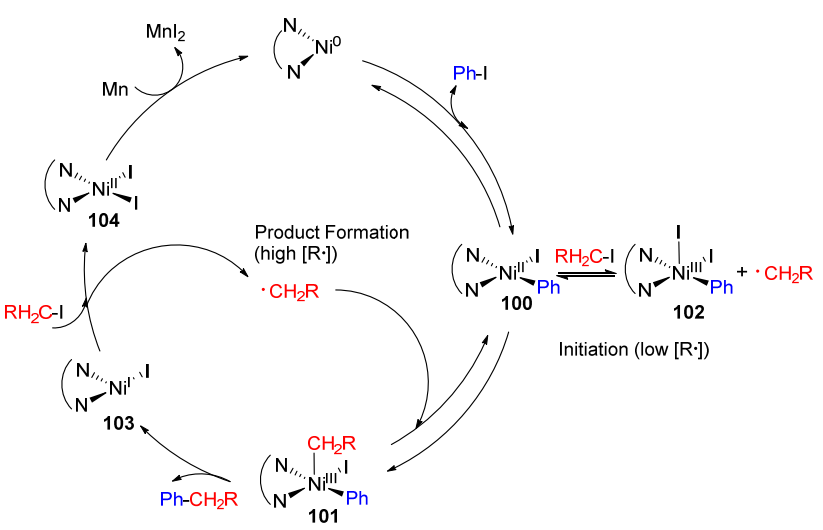

Fig. 13. Mechanism of Ni catalyzed reductive cross-coupling of an aryl halide and an alkyl halide.

reaction between 100 and alkyl iodide. The resulting complex [(L)Ni(Ph) $\left.\mathrm{I}_{2}\right]$ (102) can undergo $\mathrm{C}-\mathrm{I}$ reductive elimination to produce iodobenzene and 103. If this step is reversible, the inhibition of the reaction rate at high iodobenzene concentration can be explained. The selectivity stems from two steps: selective oxidative addition of iodoarene over iodoalkane, and selective formation of an alkyl radical over an aryl radical. This is consistent with the observations that highly reactive alkylhalides such as benzyl bromide and poorly reactive arylhalides such as iodomesitylene result in low yields of the cross-coupling product.

\section{Conclusions and outlook}

A number of novel Ni catalyzed cross-coupling reactions featuring the transformation of alkyl reagents, $\mathrm{C}-\mathrm{O}$ activation, and $\mathrm{C}-\mathrm{H}$ activation were reported in recent years. The mechanisms of these reactions are often different from the corresponding Pd catalyzed reactions. Several properties of Ni complexes may be the reasons why $\mathrm{Ni}$ catalysts are superior in some cross-coupling reactions: (1) the $\mathrm{Ni}$ atoms in low valent $\mathrm{Ni}$ complexes are less electronegative than $\mathrm{Pd}$ in the corresponding $\mathrm{Pd}$ complexes, which prompts the activation of inert C-X bonds; (2) $\beta$-H elimination from some [(L)Ni(alkyl)] intermediates are reported to be difficult $[34,35]$, an observation that can be attributed again to the low electronegativity of the $\mathrm{Ni}$ atom; (3) radical mechanisms that facilitate the activation of alkyl halides are common in Ni catalyzed cross-coupling of alkyl reagents. For these reasons, Ni catalysts can give many unique applications not available with the more popular Pd catalysts, and they have a promising future in organic synthesis.

There are still a large number of mechanistic questions in the field of $\mathrm{Ni}$ catalyzed cross-coupling reactions. The factors controlling the stereoselectivity in the cross-couplings are still elusive. Many proposed radical intermediates have not been definitively characterized. The consistency between the bimetallic mechanism and apparent kinetic behavior needs to be further examined. Further exploration of the mechanisms is very important to develop new Ni catalyzed cross-couplings with better efficiency and selectivity. We envision that future 
mechanistic studies require both experimental and theoretical endeavors to explain the reactivity and selectivity of $\mathrm{Ni}$ catalyzed cross-couplings. Furthermore, Ni catalyzed stereospecific cross-couplings are still in its early stage of development, which provides good opportunities for mechanistic studies. New types of bond activation such as $\mathrm{C}-\mathrm{H}, \mathrm{C}-\mathrm{O}$, and $\mathrm{C}-\mathrm{F}$ need better understanding of the reactivity of $\mathrm{Ni}$ complexes. The mechanistic studies of Ni catalysis will provide helpful insights into the development of new and better Ni catalyzed reactions.

\section{References}

[1] Corbet J P, Mignani G. Chem Rev, 2006, 106: 2651

[2] Magano J, Dunetz J R. Chem Rev, 2011, 111: 2177

[3] Cai S F, Wang D S, Niu Z Q, Li Y D. Chin J Catal (蔡双飞, 王定胜, 牛 志强, 李亚栋. 催化学报), 2013, 34: 1964

[4] Torborg C, Beller M. Adv Synth Catal, 2009, 351: 3027

[5] Nicolaou K C, Bulger P G, Sarlah D. Angew Chem Int Ed, 2005, 44: 4442

[6] Wang Y F, Deng W, Liu L, Guo Q X. Chin J Org Chem (有机化学), 2005, 25: 8

[7] Li Z, Fu Y, Liu L, Guo Q X. Chin J Org Chem (有机化学), 2005, 25: 1508

[8] Rosen B M, Quasdorf K W, Wilson D A, Zhang N, Resmerita A M, Garg N K, Percec V. Chem Rev, 2011, 111: 1346

[9] Jana R, Pathak T P, Sigman M S. Chem Rev, 2011, 111: 1417

[10] Tasker S Z, Standley E A, Jamison T F. Nature, 2014, 509: 299

[11] Guan B T, Wang Y, Li B J, Yu D G, Shi Z J. J Am Chem Soc, 2008, 130: 14468

[12] Ke H H, Chen X F, Feng Y Y, Zou G. Sci China Chem, 2014, 57: 1126

[13] Li Z, Zhang S L, Fu Y, Guo Q X, Liu L. J Am Chem Soc, 2009, 131: 8815

[14] Zhou J, Fu G C. J Am Chem Soc, 2003, 125: 14726

[15] Zhou J, Fu G C. J Am Chem Soc, 2004, 126: 1340

[16] Powell D A, Fu G C. J Am Chem Soc, 2004, 126: 7788

[17] Csok Z, Vechorkin O, Harkins S B, Scopelliti R, Hu X L. J Am Chem Soc, 2008, 130: 8156

[18] Zhou Q Srinivas H D, Dasgupta S, Watson M P. J Am Chem Soc, 2013, 135: 3307

[19] Harris M R, Hanna L E, Greene M A, Moore C E, Jarvo E R. J Am Chem Soc, 2013, 135: 3303

[20] Sylvester K T, Wu K, Doyle A G. J Am Chem Soc, 2012, 134: 16967

[21] Maity P, Shacklady-McAtee D M, Yap G P A, Sirianni E R, Watson M P. J Am Chem Soc, 2013, 135: 280

[22] Nielsen D K, Doyle A G. Angew Chem Int Ed, 2011, 50: 6056
[23] He A Y, Falck J R. J Am Chem Soc, 2010, 132: 2524

[24] Wang C, Ozaki T, Takita R, Uchiyama M. Chem Eur J, 2012, 18: 3482

[25] Oelke A J, Sun J W, Fu G C. J Am Chem Soc, 2012, 134: 2966

[26] Taylor B L H, Harris M R, Jarvo E R. Angew Chem Int Ed, 2012, 51: 7790

[27] Greene M A, Yonova I M, Williams F J, Jarvo E R. Org Lett, 2012, 14: 4293

[28] Taylor B L H, Swift E C, Waetzig J D, Jarvo E R. J Am Chem Soc, 2011, 133: 389

[29] Tamaru Y. Modern Organonickel Chemistry. Weinheim: Wiley-VCH, 2005

[30] Montgomery J. Angew Chem Int Ed, 2004, 43: 3890

[31] Tsou T T, Kochi J K. J Am Chem Soc, 1979, 101: 6319

[32] Lanni E L, McNeil A J. J Am Chem Soc, 2009, 131: 16573

[33] Liang T, Neumann C N, Ritter T. Angew Chem Int Ed, 2013, 52: 8214

[34] Lin B L, Liu L, Fu Y, Luo S W, Chen Q, Guo Q X. Organometallics, 2004, 23: 2114

[35] Breitenfeld J, Vechorkin O, Corminboeuf C, Scopelliti R, Hu X L. Organometallics, 2010, 29: 3686

[36] Jiang Y Y, Fu Y, Liu L. Sci China Chem, 2012, 55: 2057

[37] Li Z, Fu Y, Zhang S L, Guo Q X, Liu L. Chem Asian J, 2010, 5: 1475

[38] Li Z, Fu Y, Guo Q X, Liu L. Organometallics, 2008, 27: 4043

[39] Hartwig J F. Organotransition Metal Chemistry: From Bonding to Catalysis. New York: University Science Books, 2009

[40] Cornella J, Gómez-Bengoa E, Martin R. J Am Chem Soc, 2013, 135: 1997

[41] Zultanski S L, Fu G C. J Am Chem Soc, 2013, 135: 624

[42] Lin X F, Phillips D L. J Org Chem, 2008, 73: 3680

[43] Phapale V B, Guisan-Ceinos M, Bunuel E, Cardenas D J. Chem Eur J, 2009, 15: 12681

[44] Hu X L. Chem Sci, 2011, 2: 1867

[45] Jana R, Pathak T P, Sigman M S. Chem Rev, 2011, 111: 1417

[46] Saito B, Fu G C. J Am Chem Soc, 2007, 129: 9602

[47] Lu Z, Fu G C. Angew Chem Int Ed, 2010, 49: 6676

[48] Yi J, Liu J H, Liang J, Dai J J, Yang C T, Fu Y, Liu L. Adv Synth Catal, 2012, 354: 1685

[49] Li Z, Jiang Y Y, Fu Y. Chem Eur J, 2012, 18: 4345

[50] Tobisu M, Xu T, Shimasaki T, Chatani N. J Am Chem Soc, 2011, 133: 19505

[51] Lennox A J J, Lloyd-Jones G C. Angew Chem Int Ed, 2013, 52: 7362

[52] Liu L, Zhang S Y, Chen H, Lü Y, Zhu J, Zhao Y F. Chem Asian J, 2013, 8: 2592

[53] Gerber R, Frech C M. Chem Eur J, 2011, 17: 11893

[54] Tsou T T, Kochi J K. J Am Chem Soc, 1979, 101: 7547

\section{Graphical Abstract}

Chin. J. Catal., 2015, 36: 3-14 doi: 10.1016/S1872-2067(14)60217-5

\section{Recent advances in mechanistic studies on Ni catalyzed cross-coupling reactions \\ Zhe Li, Lei Liu* \\ Tsinghua University}

Recent advances in Ni catalyzed cross-coupling reactions including alkyl reagents, C-0 activation, and $\mathrm{C}-\mathrm{H}$ functionalization were reviewed. The mechanisms of $\mathrm{Ni}$ catalyzed reactions are usually different from the Pd catalyzed counterparts because radical and bimetallic intermediates are involved.

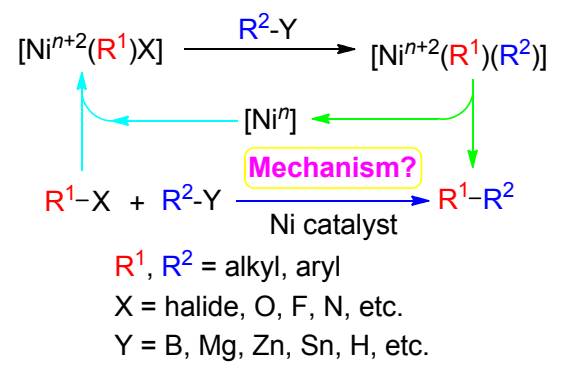


[55] Morrell D G, Kochi J K. J Am Chem Soc, 1975, 97: 7262

[56] Dubinina G G, Brennessel W W, Miller J L, Vicic D A. Organometallics, 2008, 27: 3933

[57] Huang C Y, Doyle A G. J Am Chem Soc, 2012, 134: 9541

[58] Lin B L, Clough C R, Hillhouse G L.J Am Chem Soc, 2002, 124: 2890

[59] Ney J E, Wolfe J P. J Am Chem Soc, 2006, 128: 15415

[60] Sontag S K, Bilbrey J A, Huddleston N E, Sheppard G R, Allen W D, Locklin J. J Org Chem, 2014, 79: 1836

[61] Page M J, Lu W Y, Poulten R C, Carter E, Algarra A G, Kariuki B M, MacGregor S A, Mahon M F, Cavell K J, Murphy D M, Whittlesey M K. Chem Eur J, 2013, 19: 2158

[62] Breitenfeld J, Ruiz J, Wodrich M D, Hu X L. J Am Chem Soc, 2013, 135: 12004

[63] Zheng B, Tang F Z, Luo J, Schultz J W, Rath N P, Mirica L M. J Am Chem Soc, 2014, 136: 6499
[64] Harris M R, Konev M O, Jarvo E R. J Am Chem Soc, 2014, 136: 7825

[65] Gallego D, Brück A, Irran E, Meier F, Kaupp M, Driess M, Hartwig J F. J Am Chem Soc, 2013, 135: 15617

[66] Yi J, Lu X, Sun Y Y, Xiao B, Liu L. Angew Chem Int Ed, 2013, 52: 12409

[67] Amaike K, Muto K, Yamaguchi J, Itami K. J Am Chem Soc, 2012, 134: 13573

[68] Muto K, Yamaguchi J, Itami K. J Am Chem Soc, 2012, 134: 169

[69] Hong X, Liang Y, Houk K N. J Am Chem Soc, 2014, 136: 2017

[70] Lu Q Q, Yu H Z, Fu Y.J Am Chem Soc, 2014, 136: 8252

[71] Nakao Y, Takeda M, Matsumoto T, Hiyama T. Angew Chem Int Ed, 2010, 49: 4447

[72] Jiang Y Y, Li Z, Shi J. Organometallics, 2012, 31: 4356

[73] Biswas S, Weix D J.J Am Chem Soc, 2013, 135: 16192

\title{
镍催化偶联反应机理研究进展
}

\author{
李哲, 刘 䂞* \\ 清华大学化学系, 北京 100084
}

摘要: 近期发展了很多镍催化的偶联反应作为在有机合成中高效构建 $\mathrm{C}-\mathrm{C}$ 键的方法, 同时开展了很多关于控制镍催化反应活性和 选择性的机理研究. 这些研究发现, 镍催化反应机理往往和相应的钯催化反应机理不同, 因为镍催化偶联经常包括自由基和双金 属机理. 本文总结了镍催化偶联反应机理的最新进展. 对于这些反应机理的理解为发展具有更高效率和选择性的镍催化偶联反 应提供了帮助.

关键词: 镍; 均相催化; 偶联反应; C-C键形成; 反应机理

收稿日期: 2014-08-11. 接受日期: 2014-09-04. 出版日期: 2015-01-20.

*通讯联系人. 电话: (010)62780027; 电子信箱: 1liu@mail.tsinghua.edu.cn

基金来源：国家高技术研究发展计划(863计划, 2012AA02A700); 国家自然科学基金(21221062).

本文的英文电子版由Elsevier出版社在ScienceDirect上出版(http://www.sciencedirect.com/science/journal/18722067). 